\title{
Impairment of Bolus Preparation or Mastication
}

National Cancer Institute

\section{Source}

National Cancer Institute. Impairment of Bolus Preparation or Mastication. NCI

Thesaurus. Code C127197.

An observation of an individual's bolus preparation and/or mastication prior to swallowing. 